\title{
A Technical Review on Reliability and Economic Assessment Framework of Hybrid Power System with Solar and Wind Based Distributed Generators
}

\author{
Priyanka Paliwal $^{1 *}$ \\ ${ }^{1}$ Department of Electrical Engineering, \\ Maulana Azad National Institute of Technology, Bhopal, 462003, INDIA \\ *Corresponding Author
}

DOI: https://doi.org/10.30880/ijie.2021.13.06.021

Received 16 September 2020; Accepted 14 July 2021; Available online 31 August 2021

\begin{abstract}
Recent years have witnessed an upsurge in the penetration of solar and wind power. This can be chiefly attributed to worldwide climate concern and inclination towards low carbon sources. Owing to their abundant availability, solar and wind sources are projected to play a key part in de-carbonization of power sector. However, the variability of these sources and high initial cost pose a major challenge in their deployment. Thus, reliability and economic assessment is imperative to hybrid power system(HPS) with solar and wind integration.

This paper tenders a survey on different aspects involved in reliability and economic assessment of HPS. Various techniques employed in uncertainty modelling of climatological parameters like solar irradiance and wind velocity have been deliberated. A detailed discussion on reliability evaluation parameters as well as techniques along with their merits and demerits has been carried out. In order to impart a sense of extensiveness to review, a discussion on economic evaluation metrics has also been presented. Further, author's critical comments on review along with suggestions for possible research avenues has also been presented. The review presented in this paper is envisioned to facilitate a comprehensive guide towards evaluation of solar and wind energy based HPS.
\end{abstract}

Keywords: Distributed generation, economic assessment, hybrid power system, reliability evaluation, uncertainty modelling

\section{Introduction}

Hybrid power system comprises of a fusion of generating systems based on renewable, non-renewable and storage technologies. With adequate combination of different generation technologies, hybrid systems are capable of providing increased standards of reliability and security. A hybrid power system can be planned up as an autonomous entity or can be coupled to centralized grid at the point of common coupling(PCC) [1-2]. Fig. 1 depicts a schematic of HPS comprising of solar and wind generators, connected to grid at PCC.

In remote areas with scarce population, the cost of extending grid for providing electric power could be excessively high. Autonomous HPS have emerged as a viable alternative for providing electricity access in these areas. HPS employing renewable energy sources(RES) based distributed generators(DGs) can prove to be an attractive option in comparison with fossil fuel based generators [3]. The planning of an autonomous power system is mostly concentrated on providing grid quality electricity to an area in the most reliable and economic manner. The abundant availability of solar and wind resources has led to an inclination towards utilization of these resources for autonomous as well as grid connected applications. However, the variability associated with these resources hampers the prospects of their use for autonomous applications or for utilization on grid [4]. Maintaining system reliability with of solar and wind generators is a major issue in system planning. Energy storage is seen as a viable solution for curbing the intermittency of these resources. 


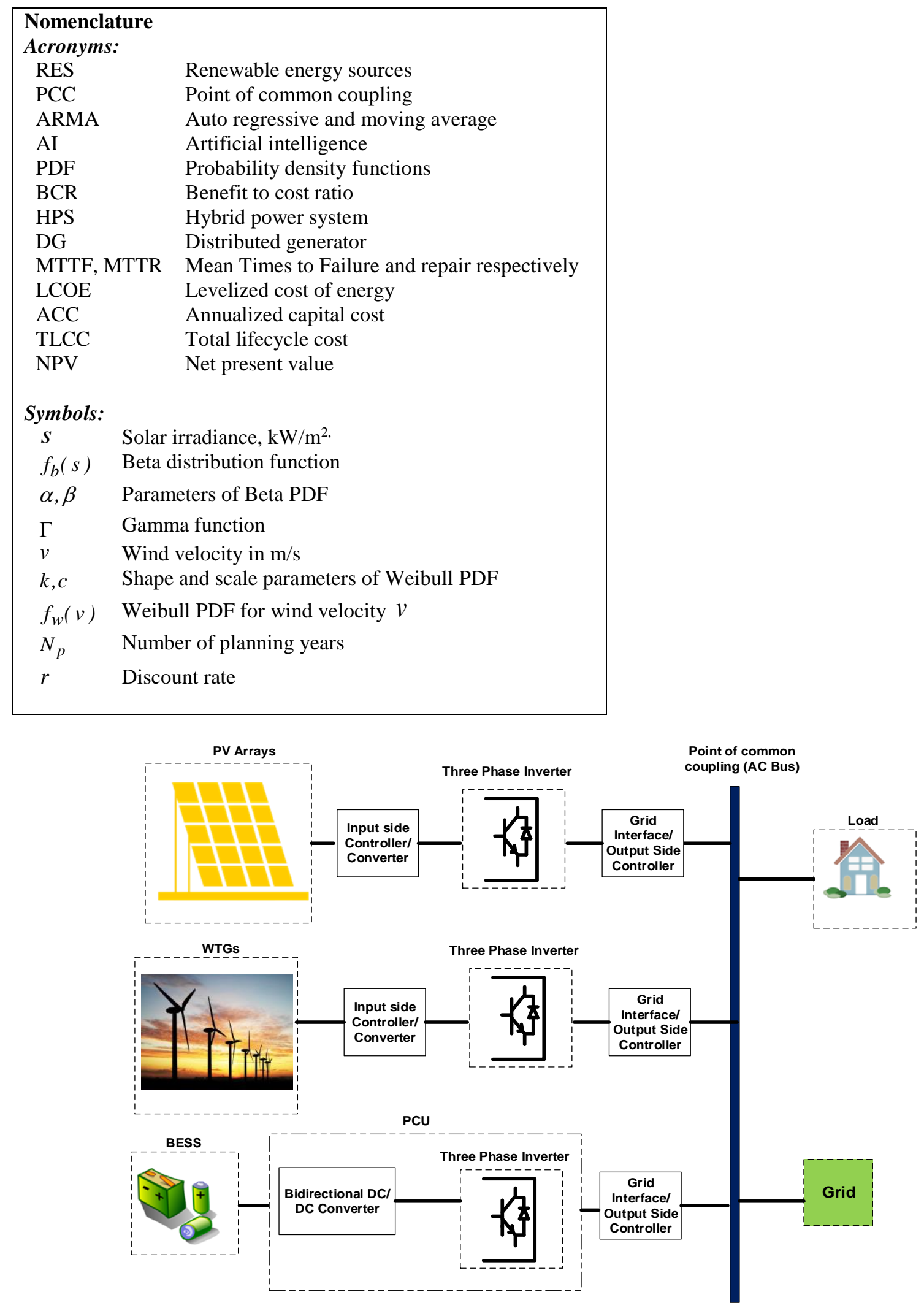

Fig. 1 - Layout of a solar-wind based HPS

Further, solar and wind generation technologies have high capital cost associated with them. Nevertheless, these technologies offer the advantage of lower operating cost as compared to conventional generating units. Thus, RES based DGs, even though capital intensive, win over diesel generators due to their lower operating costs. Thus, a careful economic evaluation with the purpose of justifying economic viability of solar-wind integration in comparison with 
conventional technologies is required. Hence, reliability and economics are two very important features of system planning with solar-wind based distributed generators.

This paper reviews current status of research in reliability and economic evaluation of HPS in presence of solar-wind based distributed generators. Fig. 2 presents a schematic representing reliability and economic evaluation framework of HPS. The reliability evaluation of systems incorporating solar-wind generators necessitates suitable modelling of climatological information viz. wind velocity and solar radiation. Thus, a discussion on different methods of modelling of these parameters has been carried out in Section 2. Section 3 is dedicated to reliability evaluation and comprises of two parts: reliability evaluation criteria and techniques. It has been found that system well-being criteria offers a robust approach in system planning and surpasses traditional deterministic and probabilistic criteria. Reliability evaluation techniques comprising of analytical and simulation based approaches have been surveyed in detail in Section 3 . The approaches have been particularly looked upon with reference to solar and wind based generators. In order to present an insight into financial assessment studies, various economic evaluation parameters as reported in literature have been surveyed in Section 4. The noteworthy conclusions from review have been summarised in Section 5.

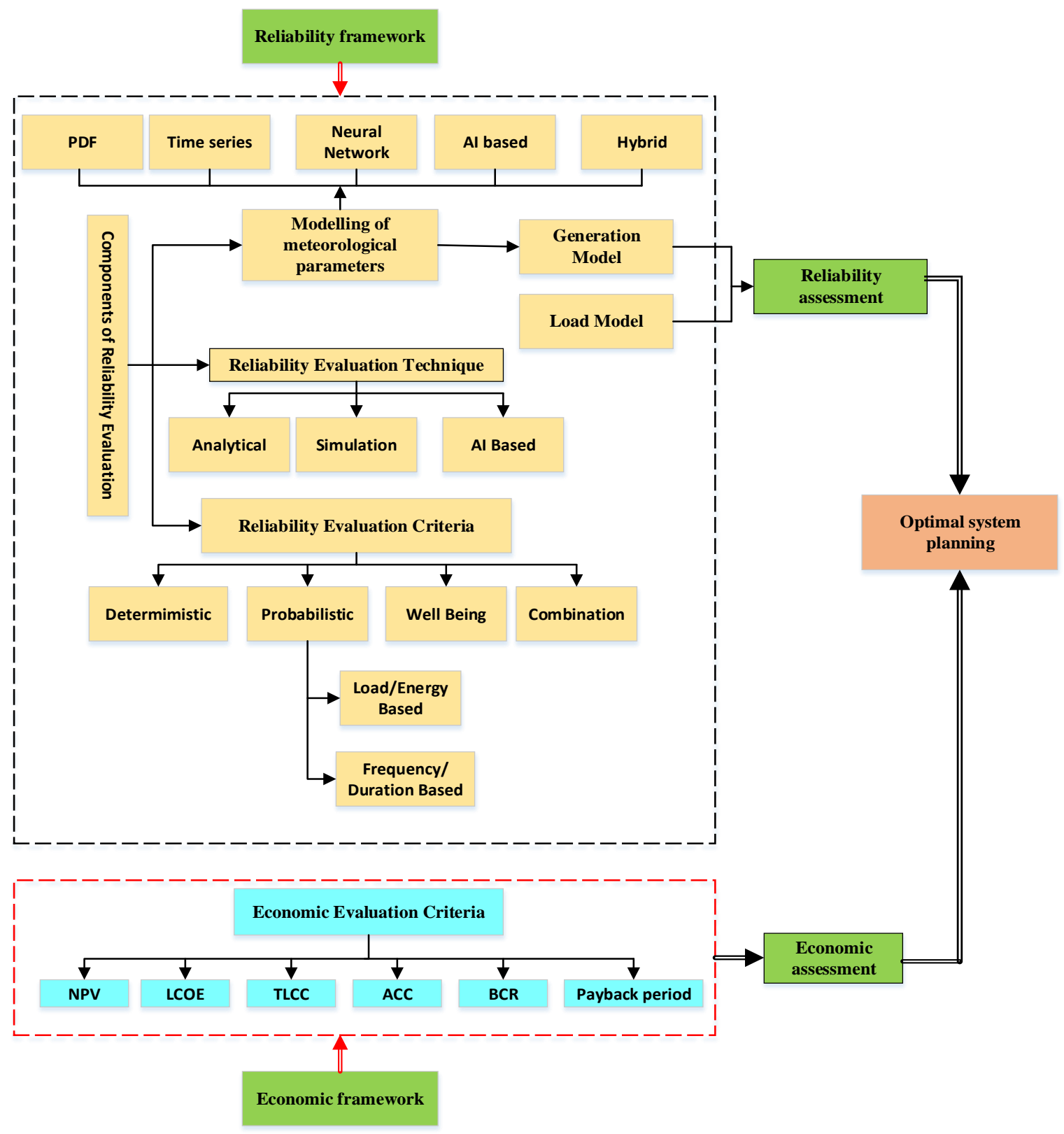

Fig. 2 - Schematic of reliability and economic evaluation framework of HPS 


\section{Modelling of Solar Irradiance and Wind Velocity}

The irradiance and wind velocity are highly intermittent parameters. Thus, determining system reliability with solar and wind generators is a challenge. Fig. 3 presents a manifestation of contribution of stochastic behaviour of RES in system reliability. The appropriate modelling of wind velocity and solar radiation is indispensable to system planning. Modelling assists in pre- assessment of solar /wind energy potential in an area which is essential for planning of a reliable and economically justifiable hybrid power system. The methods used for modelling are discussed in following subsections.

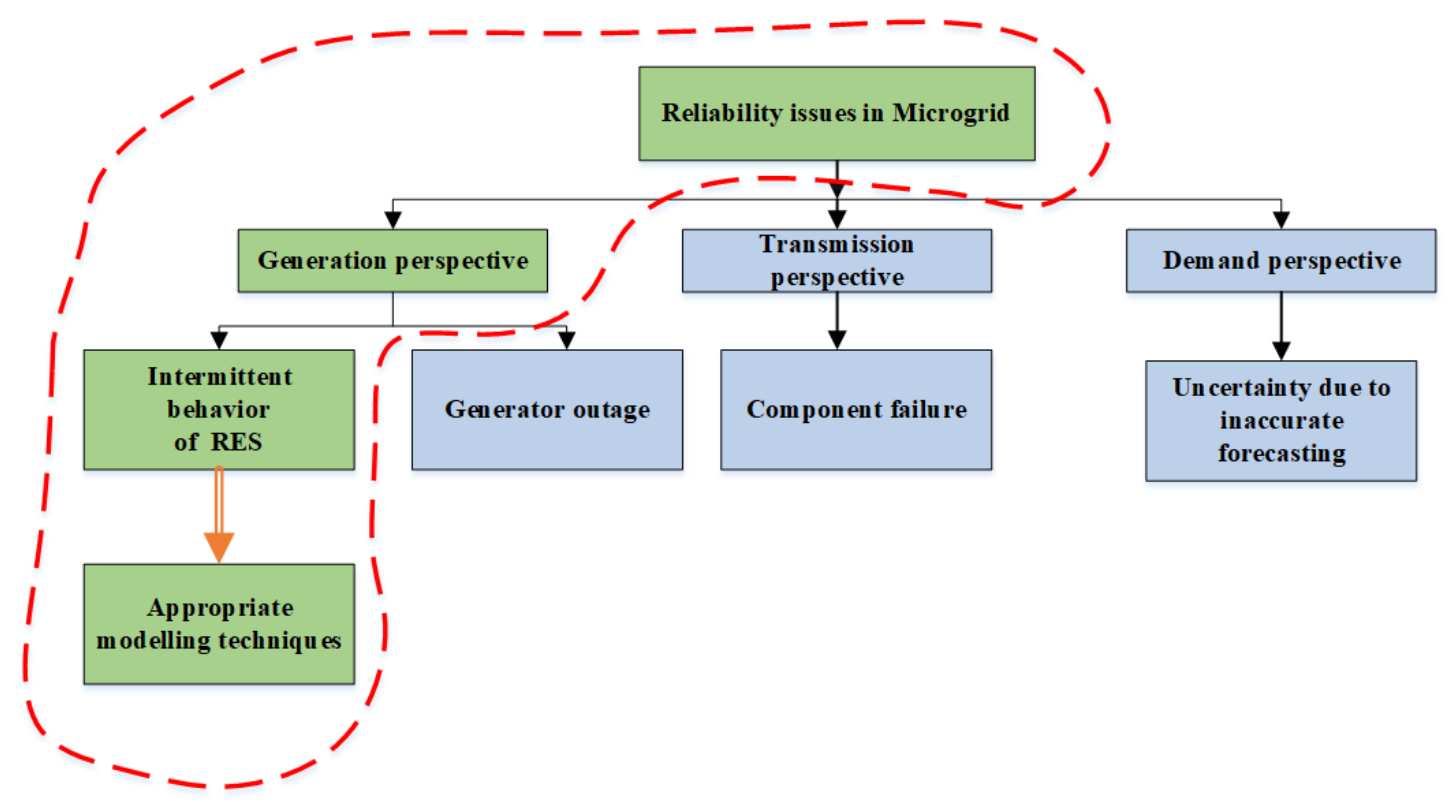

Fig. 3 - Reliability issues in micro-grid

\subsection{Modelling Using Probability Density Functions}

Probability density functions are a very prevalent method of modelling wind velocity and solar irradiance [5-12]. The irradiance and velocity are considered as stochastic parameters and assumed to follow suitable PDFs. Karaki et al. [5] have performed wind velocity modelling using Weibull PDF. Shata and Hanitsch [6] have identified Weibull parameters for 10 stations in Egypt. WASP program has been used for technical assessment. On the similar lines, Beta PDF has been used for modelling solar irradiance and Weibull pdf for wind velocity in many other references [7, 9, 1012]. Atwa et al. [7] have identified the seasonal variations in wind velocity and solar irradiance. On the basis of meteorological parameters, optimal resource mix has been determined. Khatod et al. [8] have designed HPS by considering variability of RES using PDFs. On the similar lines, Paliwal [9] has extended the analysis with HPS incorporating storage. Weibull and Lognormal distributions for modelling wind velocity have been used by Garcia $e t$ al. [13]. It has been concluded that Weibull distribution gives a better fit. Based on literature survey, it has been found that most commonly employed PDF for modelling wind velocity is Weibull and for solar irradiance is Beta PDF. These PDFs are concisely deliberated in following sections.

\subsubsection{Beta PDF for Solar Irradiance Modelling}

The Beta PDF [7-12] is represented as follows:

$$
\begin{aligned}
f_{b}(s) & =\left\{\frac{\Gamma(\alpha+\beta)}{\Gamma(\alpha) \Gamma(\beta)} s^{(\alpha-1)}(1-s)^{\beta-1} \text { for } 0 \leq s \leq 1, \alpha \geq 0, \beta \geq 0\right. \\
& =0, \text { otherwise }
\end{aligned}
$$

The parameters of PDF can be estimated once mean $\mu_{b}$ and standard deviation $\sigma_{b}$ of Beta distribution are known.

As an illustration, the modelling of solar irradiance using Beta PDF has been presented in Fig. 4. The historical data for site of Jaisalmer, India has been obtained from [14]. The PDFs have been presented for time segment 1:00- 2: 00 pm. On the similar line, PDFs for other time slots can be acquired. 

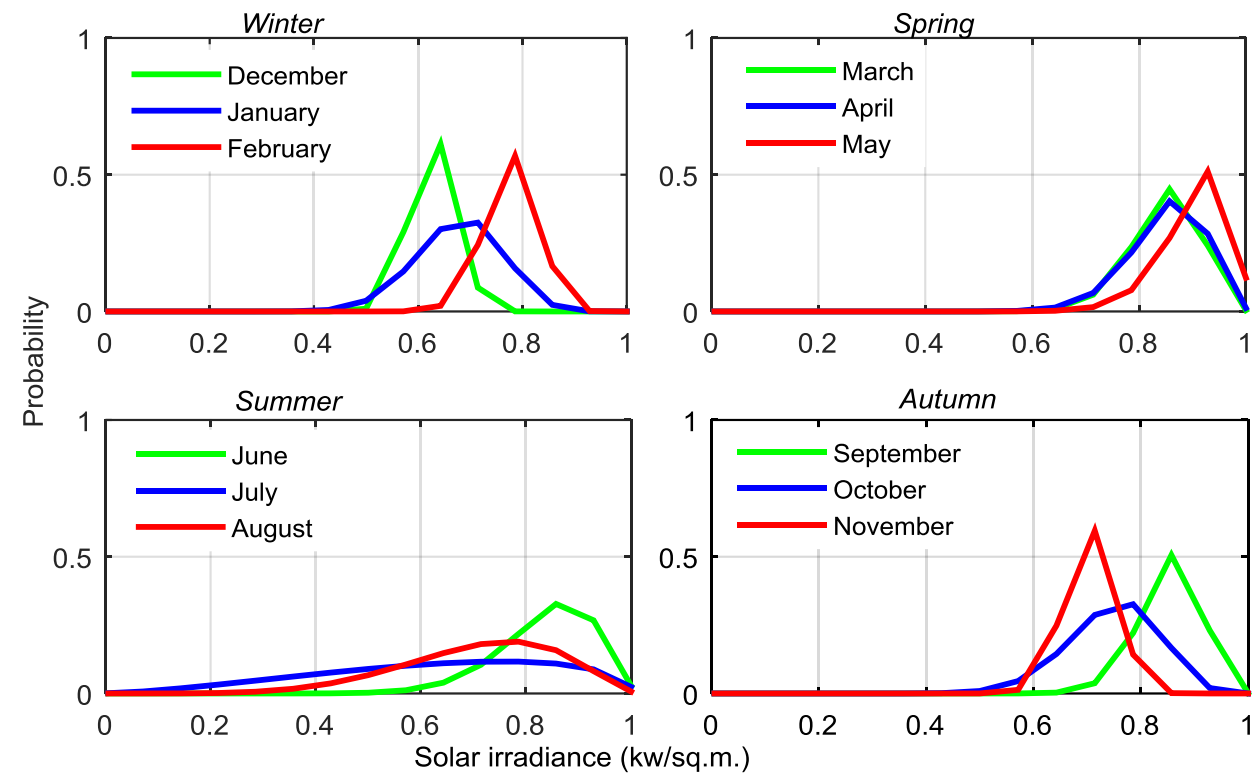

Fig. 4 - Beta PDF for time interval 1:00-2:00 p.m.

\subsubsection{Weibull PDF for Wind Velocity Modelling}

The Weibull distribution using shape and scale parameters is most widely used for modelling of wind velocity and is given by [ $5-12,15]$ :

$$
f_{w}(v)=\frac{k}{c}\left(\frac{v}{c}\right)^{k-1} e^{-(v / c)^{k}} \quad \text { for } v>0, c>1 \text { and } k>0
$$

The parameters $k$ and $c$ represent the characteristics of velocity data effectively [16]. As an illustration, the modelling of wind velocity using Weibull PDF has been presented in Fig. 5. The historical data of wind velocity for site of Jaisalmer, India has been obtained from [17]. The wind velocity data available from meteorological stations corresponds to the height at which anemometers have been installed. The measured wind velocity is extrapolated to any hub height through power law equation as follows [18]:

$$
v=v_{0}\left(\frac{h}{h_{0}}\right)^{\alpha}
$$

where, $h, h_{0}=$ hub height and reference height respectively, meters, $v, v_{o}=$ projected wind velocity and reference wind velocity respectively, $\mathrm{m} / \mathrm{s}, \alpha=$ power law exponent.
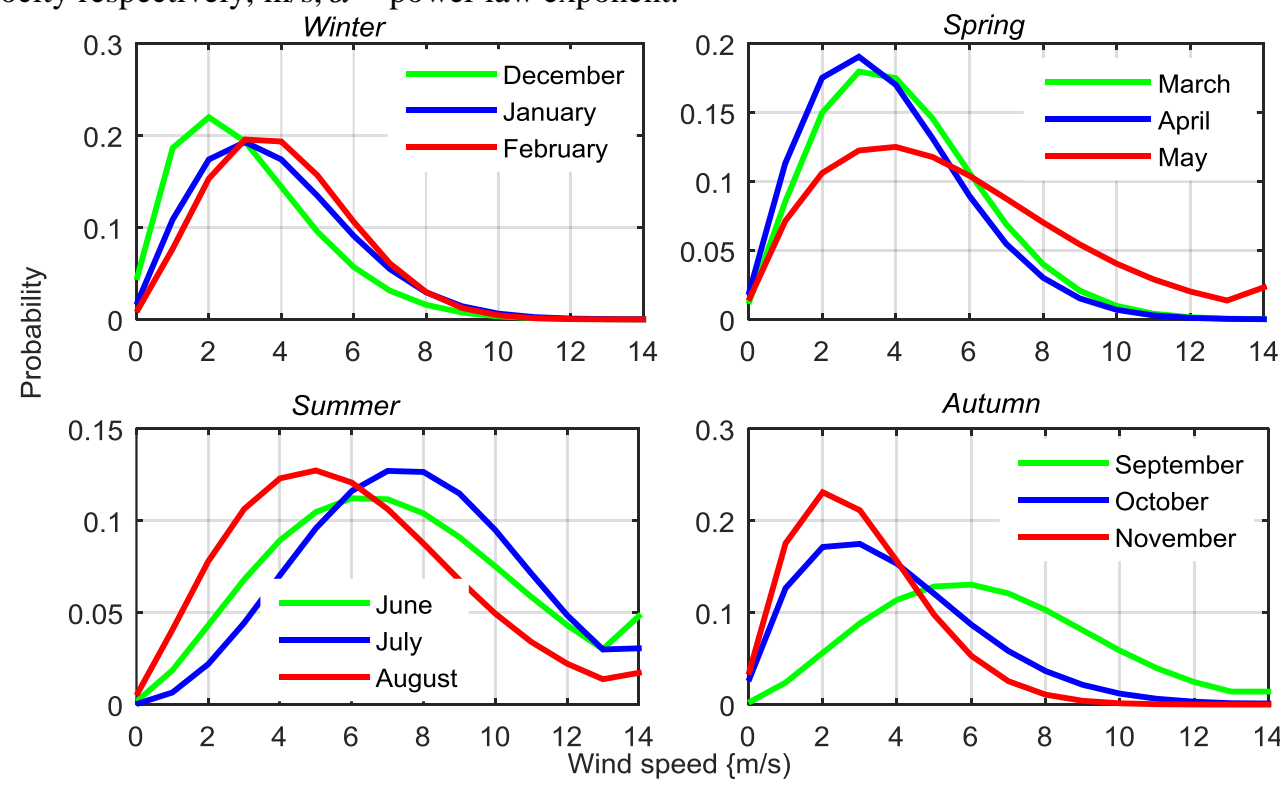

Fig. 5 - Weibull PDF for time interval 1:00-2:00 p.m. 


\subsection{Modelling Using Time Series Methods}

Time series methods [19-26] have been popularly employed for generation of wind velocity and solar radiation data. Kaminsky et al. [19] have provided a comparison of six methods of generating time series data of wind velocity. Sfetsos [20] has also provided a comparison of traditional ARMA model, feed forward and recurrent neural networks. The analysis revealed that neural logic networks produced least error. Castino et al. [21] obtained better results by combining discrete auto regressive model of second order with Markov chain. Almorox and Hontoria [22] estimated global solar radiation for 16 locations in Spain and found that third degree models give better performance. In [23], a model based on trigonometric function has been employed. Rensheng et al. [24] have used Angstro"m and Bahel model for estimating daily sunshine data in China. Sulaiman et al. [25] have used ARMA models for analysing irradiance data of Malaysia. In [26], AR -1 model has been used for generating time series of solar irradiance. ARMA models have been largely used for synthetic time series. The method can be successfully implemented for creating data sets in cases where consistency exists $[15,27]$. For a time series of data $X_{t}$, the ARMA model can be used to predict value of this series by analysing its statistical properties. Fig. 6 represents a schematic depicting steps in implementation of time series method. The model comprises of two fragments:

i. Auto regressive (AR) with order $p$

ii. Moving average (MA) with order $q$

The data series $X_{t}$ can be used to create an $\operatorname{ARMA}(p, q)$ model using following equations:

$$
X_{t}=\sum_{i=1}^{p} \phi_{i} X_{t-i}+\alpha_{t}-\sum_{j=1}^{q} \theta_{j} \alpha_{t-j}
$$

where, $\phi_{i}(i=1,2, \ldots p)$ and $\theta_{j}(j=1,2, \ldots q)$ are the AR and MA parameters of model respectively and $\alpha_{t}$ is a normal white noise process.

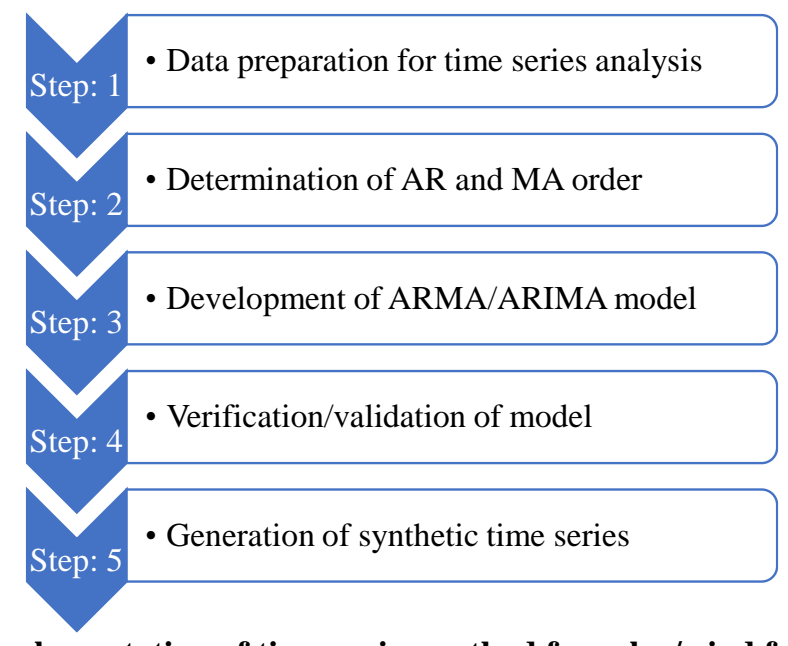

Fig. 6 - Implementation of time-series method for solar/wind forecasting

\subsection{Modelling Using Markov Chain}

Markov transition probability matrix has been widely used for generating solar irradiance and wind velocity data [27-29]. Markov Chains are stochastic mathematical systems that are characterized by assessing transition probabilities between discrete states [29]. In [30] it has been concluded that one step Markov chain model provides better generation of synthetic time series. Sahin and Sen [31] suggested that though first order Markov chain is simple to implement, the second-order can provide better results. Markovian model for wind velocity modelling has also been used by Torre $e t a l$. [32] and Shamshad et al. [29]. The observed and generated wind velocity have been compared. The statistical characteristics were found to be adequately preserved. The order of Markov chain decides the number of preceding states on which next state depends. The procedure to evaluate time series by using Markov transition probability matrix [27, 29] is as follows:

i. The observed time series is fragmented into different states.

ii. Evaluate transition probability matrix based on order of Markov chain. For $m^{\text {th }}$ order Markov chain, current state is governed by $m$ preceding states.

iii. Evaluate cumulative transition probability matrix(CTMP).

iv. Select $i^{\text {th }}$ state randomly as initial state.

v. Obtain a random number $(\mathrm{R})$ between $[0,1]$.

vi. Compare $\mathrm{R}$ with the $i^{\text {th }}$ row elements of CTMP. 
vii. If $\mathrm{R}$ is less than cumulative probability $(\mathrm{CP})$ of previous state, the previous state is adopted. Else, if it is more than $\mathrm{CP}$ of previous state but less than $\mathrm{CP}$ of following state, following state is adopted.

Using above steps, time series can be obtained.

\subsection{Modelling Using Artificial Neural Network}

Artificial neural network (ANN) has been efficaciously employed to generate wind velocity [33] and solar irradiance data sets [34]. A review on forecasting models using ANN and other artificial intelligence approaches have been provided by Lei et al. [33]. The main advantage of ANN is their ability to perform well in absence of detailed system knowledge. Kalogirou [34] has further reviewed application of ANN for solar irradiance and wind velocity forecasting. ANN consists of input, output and one or more hidden layers. In individual layers, a number of neurons are present. The former interpretations are used as input to model. The output of the model is the required forecasted value. The transfer function used for processing input is stored in the hidden layer [34-35]. Fig. 7 explains the implementation of ANN for forecasting of meteorological parameters.

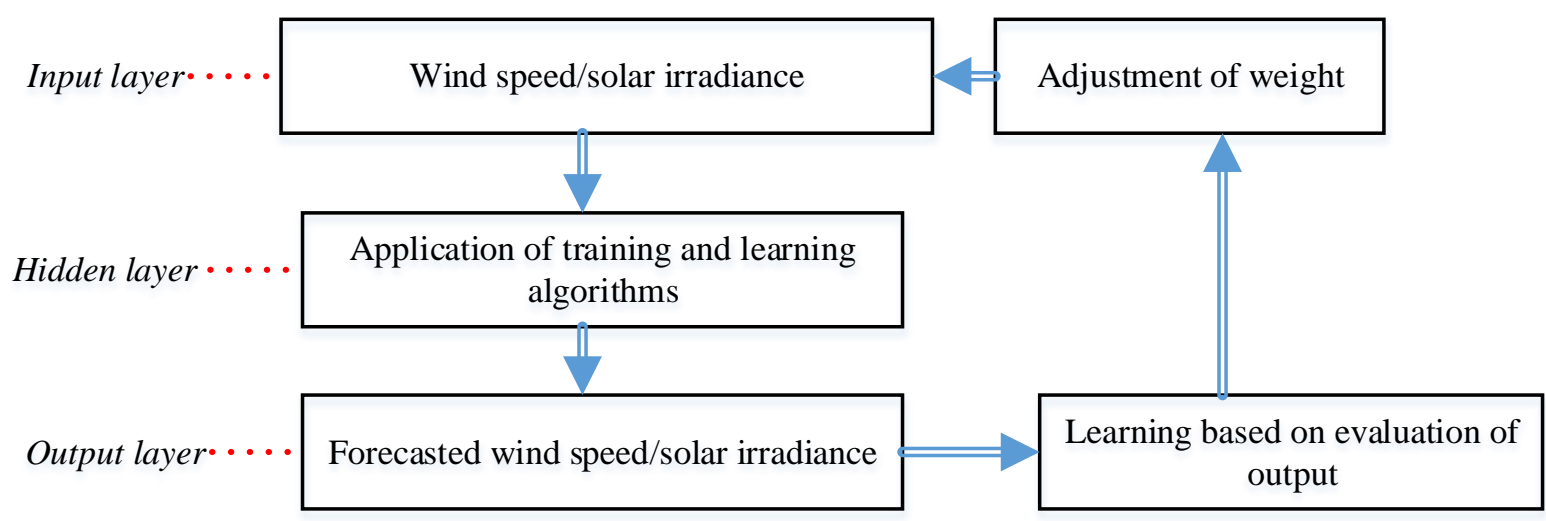

Fig. 7 - Implementation of ANN for forecasting of solar irradiance/wind velocity

Several other approaches for forecasting of wind velocity and solar irradiance have been reported in literature. Aksoy et al. [27] have used a wavelet based approach which can be used on data sets irrespective of type of distribution. Atwa and Saadny [36] have used constrained grey predictor model to assess wind velocity profile. Type-2 Fuzzy neural network [37], wavelet-neural network [38], wavelet decomposition-AdaBoost technique [39], adaptive neuro-fuzzy inference system [40] and artificial intelligence based techniques [41] have also been used. A review performed in [42] have reported other techniques such as numerical weather prediction and hybrid forecasting models for forecasting solar irradiance. Al Muhaini et al. [43] have performed a comparative study on the effect of wind velocity modelling technique on reliability assessment.

A summary of review on modelling of meteorological parameters has been presented in Table 1.

Table 1 - Review on methods of modelling of meteorological parameters

\begin{tabular}{|c|c|c|c|c|c|c|}
\hline Technique & Ref. & $\begin{array}{l}\text { Meteorological } \\
\text { parameter }\end{array}$ & $\begin{array}{l}\text { Technique } \\
\text { description }\end{array}$ & $\begin{array}{l}\text { Site under } \\
\text { study }\end{array}$ & Benefits & Limitations \\
\hline PDF & $\begin{array}{l}{[9]} \\
{[10]} \\
{[11]} \\
{[12]} \\
{[13]} \\
{[44]}\end{array}$ & $\begin{array}{l}\text { Wind velocity, } \\
\text { solar irradiance } \\
\text { _“- }\end{array}$ & \begin{tabular}{l}
-“- \\
\multicolumn{1}{c}{-“- } \\
Weibull, \\
Lognormal \\
Beta, Weibull
\end{tabular} & $\begin{array}{l}\text { Not specified } \\
\text { Mediterranean } \\
\text { coast } \\
\text { Rural } \\
\text { distribution } \\
\text { system } \\
\text { Kandla port, } \\
\text { India } \\
\text { Jaisalmer, } \\
\text { India } \\
\text { Jaisalmer, } \\
\text { India } \\
\text { Jaisalmer, } \\
\text { India } \\
\text { Zhoushan } \\
\text { Navarre, Spain }\end{array}$ & $\begin{array}{l}\text { - Can provide the } \\
\text { modelling of } \\
\text { wind velocity } \\
\text { and solar } \\
\text { irradiance } \\
\text { without the } \\
\text { necessity of } \\
\text { other } \\
\text { meteorological } \\
\text { information. } \\
\text { - Realistic } \\
\text { seasonal } \\
\text { prediction. }\end{array}$ & $\begin{array}{l}\text { - The selection of } \\
\text { states while } \\
\text { discretizing the } \\
\text { continuous } \\
\text { function largely } \\
\text { affects the } \\
\text { system accuracy. }\end{array}$ \\
\hline
\end{tabular}




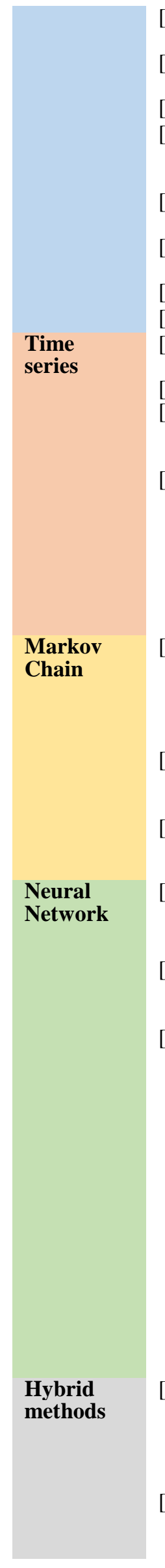

[45]

[46]

[47]

[25]

$[26]$

[53]

[54]

Solar irradiance
Wind velocity,

solar irradiance

Wind velocity

[19]

Solar irradiance

Wind velocity

Type-2 Fuzzy Neural

Network

One step
Markov chain

Box Jenkins,

Shinozuka

model

First and

second order

Markov chain -“- Turkey

network

LSTM neural network

India

Hormoz

India

Brazil
Wavelet-

Jaisalmer,

Island, Iran

Not specified

La Gomera,

Canary islands

Dammam city,

Saudi Arabia

Jaisalmer,

Milas, Turkey

Not specified

Malaysia

Kythnos

island, Greece

Toronto,

Canada

Windsor, Mass • Higher order

Markov chains

can provide accurate

forecasting and reduces prediction error.

Prince Edward Island, Canada

- Eliminates the necessity of mathematical implementation inherent to statistical approaches.

- Caters appropriately to non-linearity associated with randomness of solar and wind.

- Responsive to online measurement and consequent training.

- Suitable for short as well as long term forecasting.

[20] Wind velocity

ARMA, feed Odigitria,

- Facilitate

forward and Greek island of fusion of best

[21] features of different models.

- Improved accuracy. recurrent $\mathrm{NN}$, Crete

Adaptive

Neuro-Fuzzy

$\begin{array}{lll} & \begin{array}{l}\text { forward and } \\ \text { recurrent NN, }\end{array} & \text { Greek island of } \\ \text { Adaptive } & \\ \text { Neuro-Fuzzy } & \\ \text {-“- } & \begin{array}{l}\text { Markov chain } \\ \text { and discrete }\end{array} & \text { Brindisi } \\ & \text { AR model }\end{array}$

Requires large amount of

historical data.

- Inability to

capture nonlinearity associated with wind velocity and solar irradiance.

- Unsuitable for long-term forecasting.

- Complexity increases with increase in order.

- Selection of appropriate training method is essential for accurate and fast forecast.

- Requires large amount of data for training.
- Complex to implement. This limits their application for short term forecasting.

- Requires expertise of 


\begin{tabular}{|c|c|c|c|}
\hline [22] & Solar irradiance & $\begin{array}{l}\text { Angstrom-- } \\
\text { Prescott linear } \\
\text { regression }\end{array}$ & $\begin{array}{l}16 \\
\text { meteorological } \\
\text { stations in } \\
\text { Spain }\end{array}$ \\
\hline [23] & -“" & $\begin{array}{l}\text { Trigonometric } \\
\text { function based } \\
\text { model }\end{array}$ & Turkey \\
\hline [24] & -“'- & $\begin{array}{l}\text { Angstro"m } \\
\text { model, Bahel } \\
\text { model }\end{array}$ & China \\
\hline [27] & Wind velocity & $\begin{array}{l}\text { Weibull, First } \\
\text { order Markov, } \\
\text { Wavelet }\end{array}$ & $\begin{array}{l}\text { Diyarbakir, } \\
\text { Anatolian }\end{array}$ \\
\hline [36] & _“'- & $\begin{array}{l}\text { Grey predictor } \\
\text { model }\end{array}$ & Not specified \\
\hline [39] & -“- & $\begin{array}{l}\text { Wavelet } \\
\text { decomposition } \\
\text { and AdaBoost } \\
\text { technique }\end{array}$ & East China \\
\hline [40] & -“6 & $\begin{array}{l}\text { Adaptive } \\
\text { neuro-fuzzy }\end{array}$ & $\begin{array}{l}\text { Sichuan } \\
\text { province, } \\
\text { China }\end{array}$ \\
\hline$[58]$ & Hydro power & $\begin{array}{l}\text { Neural fuzzy } \\
\text { inference } \\
\text { model and } \\
\text { PSO }\end{array}$ & Vietnam \\
\hline
\end{tabular}

\section{Discussion on Reliability Evaluation}

The reliability is the likelihood of providing power system customers with uninterrupted supply at a voltage and frequency level within defined standards [59]. The HPS must be able to supply power with adequate levels of reliability. Reliability evaluation is particularly significant in HPS employing solar-wind based distributed generators due to stochastic nature of these resources $[1,9]$.

\subsection{Reliability Evaluation Criteria}

The basic reliability criteria used in system planning studies are briefly discoursed in subsequent sub-sections.

\subsubsection{Deterministic Criteria}

The deterministic methods are amongst the preliminary techniques used by utilities to decide required generating capacities. Billinton and Karki [60] asserted that deterministic criteria are acceptable only for small isolated power systems. However, for large power systems they are not found suitable to provide adequate information. The authors [61] further emphasized the incapability of deterministic criteria to assess actual risk. Common deterministic approaches involve comparison of reserve capacity which is available in the system with [8, 59-61]:

i. a fraction of total capacity

ii. capacity of largest generator

iii. capacity of largest generator along with a fraction of peak demand.

Deterministic domain which feels very secure and comfortable does not offer a very practical approach to planning problem. The limitations of deterministic methods are as follows [59]:

- Inability to reflect random response of system, consumer demands and component failures.

- Forced outage rates of generating units are correlated with size and type of generating units. Therefore, a fixed percentage reserve cannot lead to appropriate system evaluation.

- Inability of load forecasting techniques to provide exact load prediction.

\subsubsection{Probabilistic Criteria}

Due to limitations of deterministic approaches, probabilistic methods [62-63] became evident during 1930s. Pioneering efforts over a period of time resulted in extensive development of probabilistic indices, viz. LOLP, LOLE, LOEE and Frequency and Duration (FAD) index. The generation units are modelled by using respective MTTF and MTTR rates. The probabilistic techniques capture randomness inherently present in system and hence provide a more sophisticated approach to reliability evaluation as compared to deterministic criteria. The most commonly employed reliability index is loss of power supply probability (LPSP). The planning of an isolated solar-wind plant has been realized using LPSP as the base [12, 53, 62, 64] in various references. Ma et al. [12] have used a constrained reliability set up to design a standalone HPS. In Ref. [53], the battery capacity is optimized so as to confine LPSP within desired 
limits. Yang et al. [64] have considered scenario based planning to design a HPS with LPSP as a constraint. A comparison w.r.t. traditional simulation based technique has also been performed. Loss of load probability [65-66] and Expected energy not served(EENS) [59] have also been extensively used for reliability assessment. Mathew et al. [65] have used LOLP and LOEE as an indicator of reliability. There are several studies reported in literature which are directed towards system planning based on reliability and economics. In some of the references, frequency and duration indices (FAD) have also been reported [59-60]. Conti et al. [70] have proposed a generalized approach considering load shedding policies. Distribution system reliability assessment has been done using SAIFI and SAIDI. In Ref. [71], Bagheri et al. have aimed at distribution network expansion planning considering system uncertainties. Unlike, probabilistic indices such as LOLP, LOLE, EENS, the FAD takes into account the duration of outage. Thus, they offer a distinct approach to reliability evaluation studies. In some references, a combination of load/energy based indices and FAD indices have been used to provide enhanced assessment of system reliability [72-74]. Chen et al. [73] have performed multi-microgrid system reliability assessment using SAIFI, SAIDI and EENS. In a recent work [74], reliability evaluation of micro-grid has been done considering the equipment failure. Two reliability models comprising of component and system reliability have been developed.

Nevertheless, probabilistic approaches have certain drawbacks associated with them. The limitations of probabilistic methods are as follows [59]:

- Absence of suitable data on generating unit and factual load demand.

- Lack of information regarding capacity reserves available during system operation.

Table 2 - Classification of literature based on reliability indices

\begin{tabular}{|c|c|c|c|c|}
\hline Category & Ref. & Reliability Index & Benefits & Shortcomings \\
\hline \multirow{3}{*}{ Probabilistic } & [5] & EENS, EIR & \multirow{13}{*}{$\begin{array}{l}\text { - Simple to implement. } \\
\text { - Useful for generation } \\
\text { adequacy evaluation }\end{array}$} & - Concerned only with \\
\hline & [9] & EENS, LOLE & & the loss of load, cannot \\
\hline & {$[47]$} & $\begin{array}{l}\text { EENS, Energy index of } \\
\text { reliability }\end{array}$ & & $\begin{array}{l}\text { small and large } \\
\text { capacity shortage. }\end{array}$ \\
\hline Subcategory: & {$[56]$} & EENS, EIR & & \\
\hline \multirow{9}{*}{$\begin{array}{l}\text { Load /Energy } \\
\text { based indices }\end{array}$} & {$[12]$} & LPSP, LEP & & \multirow{9}{*}{$\begin{array}{l}\text { - Do not consider the } \\
\text { frequency and duration } \\
\text { of the shortage. }\end{array}$} \\
\hline & {$[65]$} & LOLP, LOEP & & \\
\hline & {$[66]$} & LPSP, Total energy loss & & \\
\hline & [44] & ENS & & \\
\hline & {$[55]$} & LOLE, LOLF,EENS & & \\
\hline & {$[67]$} & LOLP & & \\
\hline & [49] & EENS & & \\
\hline & {$[68]$} & LPSP & & \\
\hline & [69] & LPSP, LOEE, LOLE & & \\
\hline \multirow{3}{*}{$\begin{array}{l}\text { Probabilistic } \\
\text { Subcategory: } \\
\text { Frequency and } \\
\text { duration based } \\
\text { indices }\end{array}$} & [43] & SAIFI, SAIDI & \multirow{9}{*}{$\begin{array}{l}\text { - Information regarding type } \\
\text { of outage } \\
\text { - Provides information } \\
\text { regarding frequency and } \\
\text { duration of outage. } \\
\text { - Useful for customer or load } \\
\text { point evaluation. } \\
\text { - Provides the best features of } \\
\text { both the categories of } \\
\text { indices. } \\
\text { - Useful for assessment of } \\
\text { generation adequacy as well } \\
\text { as customer end reliability }\end{array}$} & \multirow{3}{*}{$\begin{array}{l}\text { - Comparatively } \\
\text { complex. }\end{array}$} \\
\hline & {$[70]$} & -“ & & \\
\hline & {$[71]$} & -“'- & & \\
\hline \multirow{6}{*}{$\begin{array}{l}\text { Combination of } \\
\text { Load/Energy and } \\
\text { Frequency based } \\
\text { indices }\end{array}$} & {$[72]$} & SAIFI, SAIDI, EENS & & \multirow{6}{*}{$\begin{array}{l}\text { - Too many indices to } \\
\text { evaluate } \\
\text { - More complex }\end{array}$} \\
\hline & [73] & 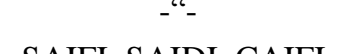 & & \\
\hline & [74] & $\begin{array}{l}\text { SAIFI, SAIDI, CAIFI, } \\
\text { EENS }\end{array}$ & & \\
\hline & {$[54]$} & $\begin{array}{l}\text { Probability of health, } \\
\text { Probability of Risk, } \\
\text { Probability of Margin }\end{array}$ & & \\
\hline & & $\begin{array}{l}\text { Probability of health, } \\
\text { Probability of Risk, } \\
\text { Probability of Margin }\end{array}$ & & \\
\hline & & $\begin{array}{l}\text { EENS, LOLE, Well- } \\
\text { being indices }\end{array}$ & & \\
\hline
\end{tabular}




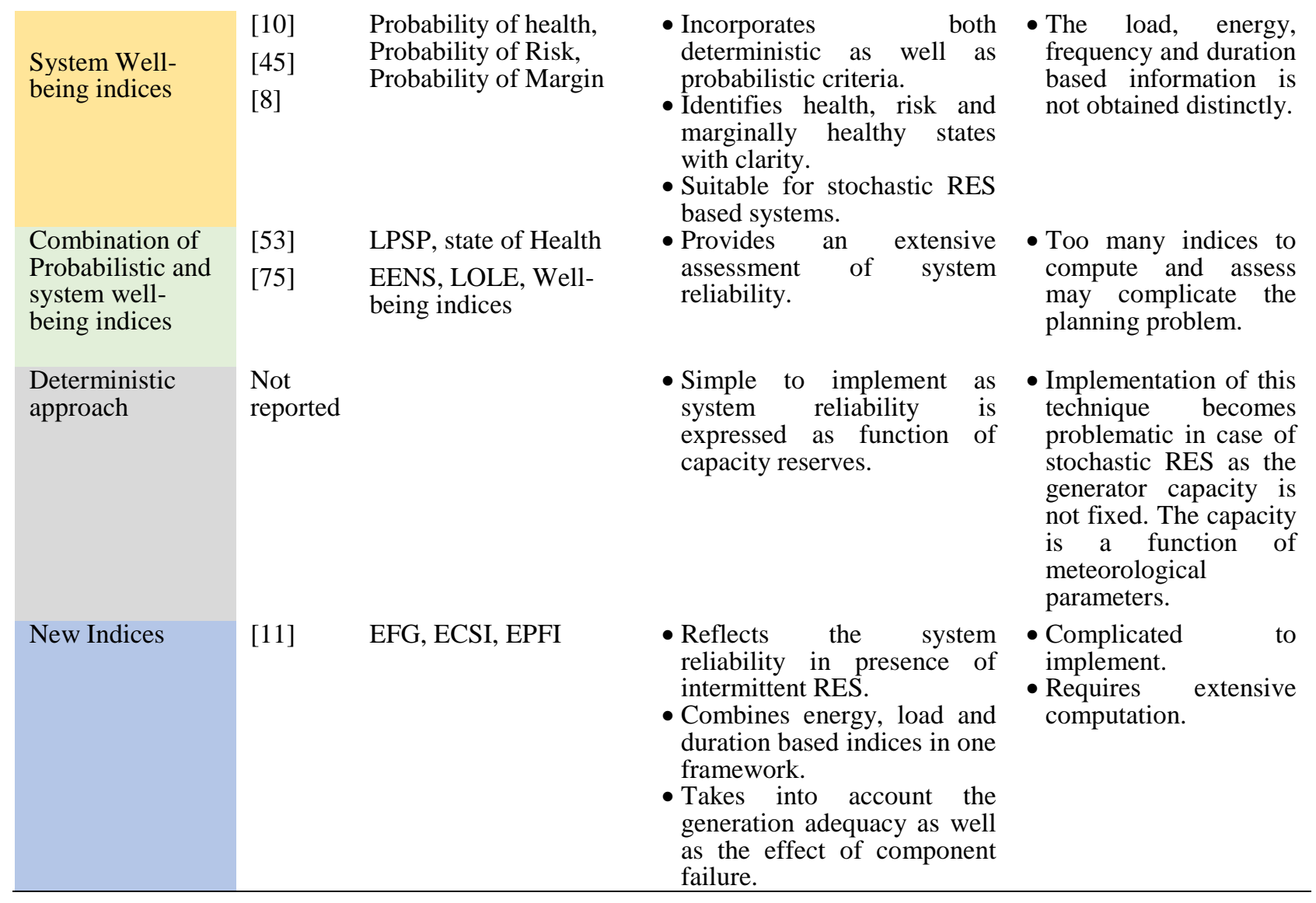

\subsubsection{System Well-Being Criteria}

To overcome the problems posed by deterministic and probabilistic methods, system well-being technique was introduced in 1990s. System well-being criteria [8-10] embeds deterministic criterion in a probabilistic framework and includes security consideration for system planning and operating studies. System well-being criteria has been primarily used in several reliability evaluation studies conducted by Billinton and Karki. Khatod et al. [8] and Paliwal et al. [10] have used it for reliability evaluation planning of autonomous power system comprising of solar and wind. It was asserted that well-being indices offered an improved indication of system reliability. Thapa et al. [54] have used conditional probability approach for well-being analysis. The well-being model $[61,76]$ is presented in Fig. 8.

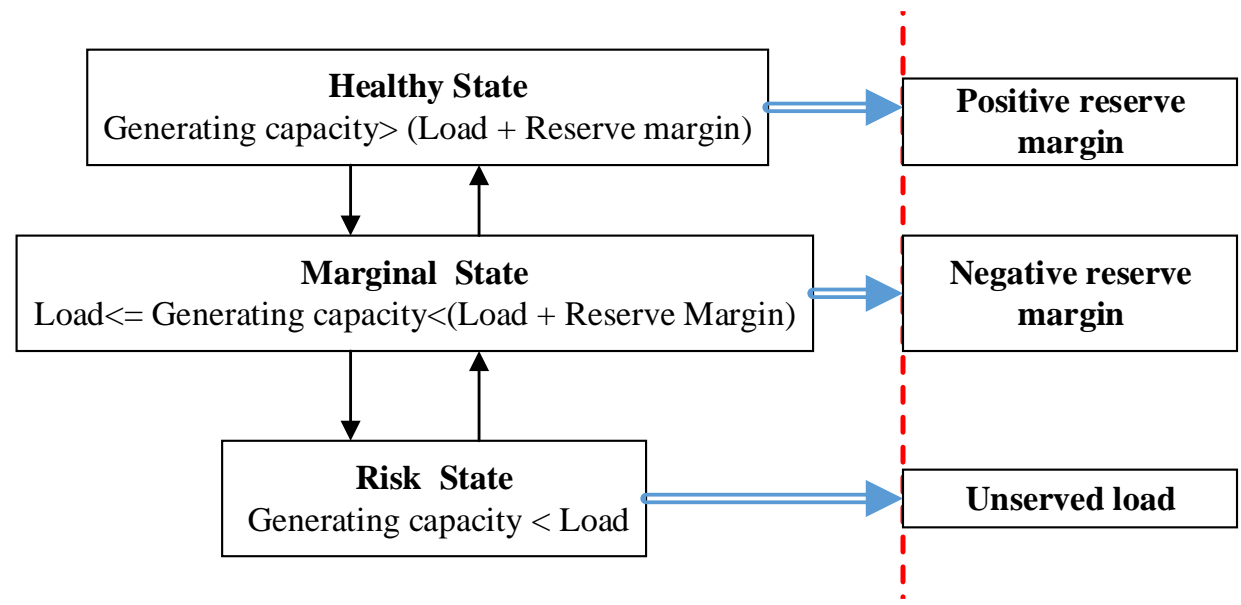

Fig. 8 - System well-being model 
As evident from Fig. 8, the system belongs to one of the following states:

- Healthy: sufficient reserves to meet the requisite deterministic criteria. The associated probability is referred to as Healthy State Probability.

- Marginal: enough generation to meet the load but insufficient reserves to meet requisite deterministic criteria. The associated probability is referred to as Marginal State Probability.

- Risk: generation is insufficient to cater load requirement. The associated probability is referred to as Risk State Probability.

System Well-Being Criteria comprising of healthy, risk and marginal system states offers a practical approach to system planning and has been widely used. The well-being indices can be particularly helpful in case of isolated HPS. Due to absence of grid, it is desirable to have some amount of reserves in isolated HPS. This information can be provided by well-being indices.

A classification of literature based on reliability indices along with their benefits and limitations has been presented in Table 2.

\subsection{Reliability Evaluation Techniques}

The most widely used reliability evaluation techniques comprise of analytical and simulation methods. Recently, the research has also been directed towards deployment of artificial intelligence techniques. A discussion on these approaches is presented as follows:

\subsubsection{Analytical Technique}

In this technique, the mathematical modelling of system is done to provide a direct solution [59]. The computational time is very less. However, if system is too complex, then assumptions made to simplify the system can override the accuracy. Therefore, analytical technique is not considered very suitable for complex systems. The analytical technique may be based on enumeration technique or population based approaches. The enumeration based approaches build up a probabilistic model of system capacity states. Amongst the research on enumeration techniques, a closed form solution approach is used for measuring reliability indices for wind and photovoltaic system [62]. Gavanidou et al. [63] have used probabilistic method for evaluating wind-diesel systems wherein wind velocity and load have been treated as discrete random variables and their various states and corresponding probabilities have been computed from their respective PDFs. On the similar lines, Karaki et al. [47] have obtained wind farm model from joint distribution of available wind power modelled through Weibull distribution and operating modes of wind turbines. Saramourtsis et al. [78] have used analytical technique for reliability assessment. The results obtained have been found to be comparable with those obtained from simulation with much lesser calculation time. Similar observations have been quoted by Khatod et al. [8] where analytical method is applied for assessment studies of an isolated system comprising of diesel generator, solar and wind energy sources. The analytical technique reported results with comparable accuracy and significantly reduced computation time as compared to MCS. The analytical technique has also been implemented for hybrid systems incorporating storage [5, 9-11].

\subsubsection{Simulation Technique}

Simulation based approaches treats problem as a series of experiments. They portray a significant ease of implementation, although at the expense of more computation time. The simulation techniques can be categorized into deterministic and Monte Carlo Simulation(MCS) [59]. Deterministic simulation does not incorporate uncertainties associated with the system behaviour. In contrast, MCS includes uncertainties associated with system behavior. MCS has been used by Billinton and Karki [76] for evaluating well-being indices. The outage history of generating units has been generated by using exponential PDF. The authors further extended the analysis to an isolated power system using solar and wind energy sources [79]. Integration of electric energy storage has been seen as a powerful solution in order to deal with intermittency associated with these resources. MCS has also been applied for systems with battery storage.

\subsubsection{Population Based Technique}

The population based methods make use of meta-heuristics for evaluation of reliability indices. The deployment of optimization techniques significantly reduces the search space. The mechanism of implementation of these techniques facilitate the selection of states with higher failure probabilities. This intelligent state selection makes this method computationally less cumbersome. Benidris et al. [67] have used a state space classification technique based on PSO. Letie Da Silva et al. [75] used artificial neural network for determining well-being indices. Wang et al. [55] have provided an interesting alternative to MCS by using population based search intelligent search (PIS). A summary of reliability techniques from literature has been reported in Table 3. A comparison between these techniques in terms of benefits and shortcomings has also been provided. On surveying the techniques of reliability assessment, it may be concluded that MCS has been extensively used for reliability evaluation. The simulation approach is computationally expensive and may prove inefficient when large numbers of combinations of generating units are to be evaluated. 
Table 3 - Summary of reliability evaluation techniques

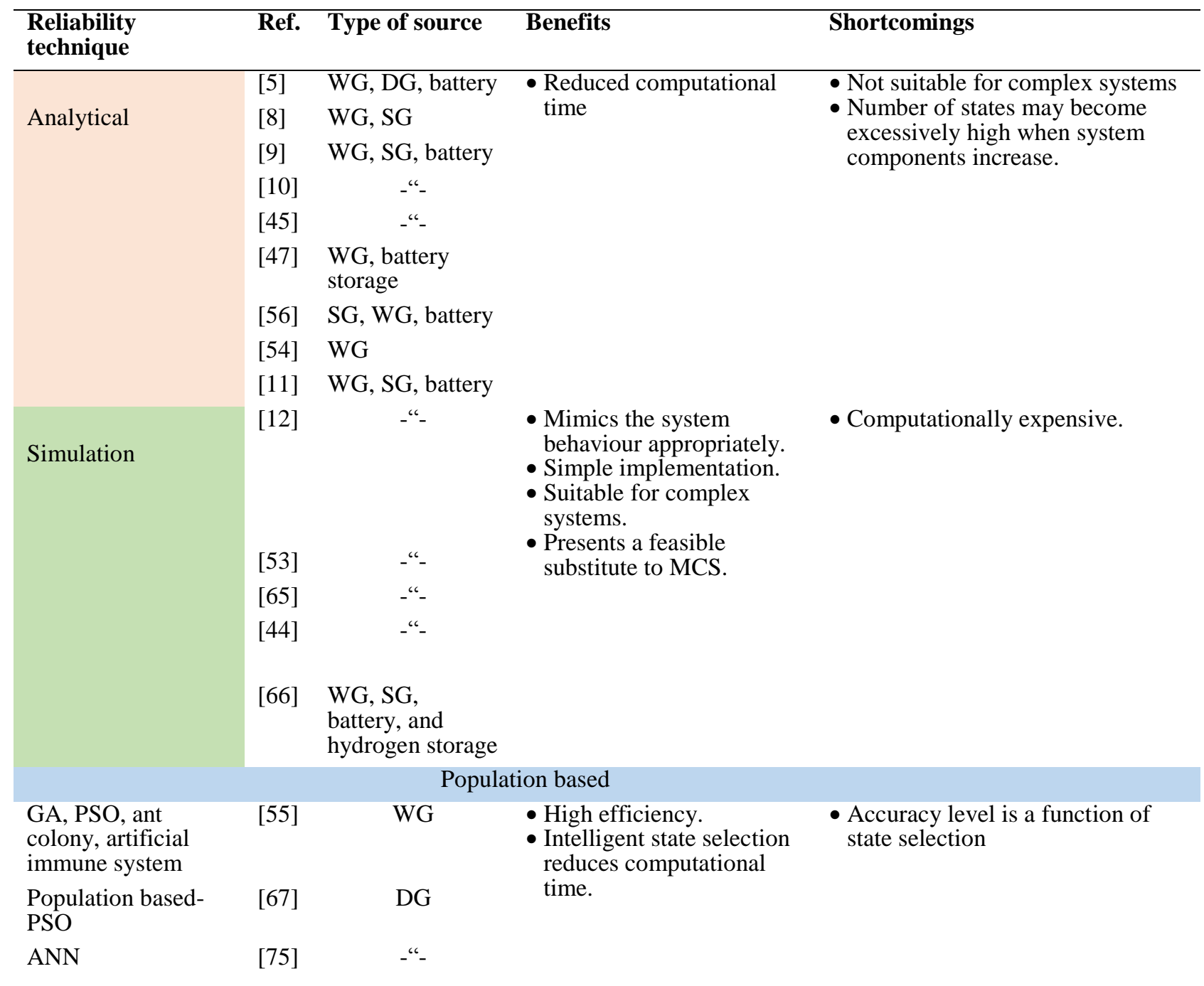

WG: Wind generator, SG: Solar generator, DG: Diesel generator

\section{Economic Evaluation}

Economic evaluation forms a fundamental constituent of system planning. The goal of economic evaluation is to assist system planners to come up with an optimal system design with requisite standards of reliability [80]. The optimal system planning has to be carried out over project lifespan. Thus, it considers all costs encountered in the planning period. There is a wide variety of economic criteria being used by utilities. However, the perspective of planning determines the type of criteria incorporated in planning process. While designing system using RES based DGs, a gruelling analysis acknowledging the non-monetary benefits such as environmental emissions, diversification from conventional fossil fuels should be carried out in order to provide a backing to such projects. In [5], a useful economic analysis has been presented which indicates the point beyond which no more generating capacity addition should be done. Matthew et al. [65] have performed a sensitivity analysis of levelized cost of energy. Analysis has been done in conjunction with demand response program. Bakhtiari and Naghizadeh [66] have used a multi-criteria approach to obtain maximum reliability while minimizing TLCC. Paliwal [45] has performed a sensitivity analysis based on TLCC. In addition, a parameter called as Incremental cost of reliability has also been used. TLCC has also been adopted for planning of storage in a solar-winddiesel based HPS [53]. Saberi et al. [46] have included cost of unserved energy in TLCC. Mellouk et al. [81] have developed a new method to assess cost associated with storage charging/discharging and include this in total system costs. A multi-objective formulation has been proposed [56] based on reliability, TLCC and emission parameters. LCOE reflects the actual per unit cost of energy and offers a very practical approach to economic evaluation. LCOE has been used as a key parameter in different planning analysis [10]. A comparative study on diesel-solar hybrid and solar alternatives has been performed based on LCOE [82]. Jafari et al. [44] have tried to optimize conflicting objective function based on system costs and demand response program. A summary of economic evaluation parameters reported 
in literature along with their benefits and limitations is presented in Table 4. Some of the important economic criteria reported in literature are as follows:

i. Net Present Value (NPV):

$$
N P V=\sum_{n=0}^{N_{p}} \frac{F_{n}}{(1+r)^{n}}
$$

where, $F_{n}=$ net cash flow in $n^{\text {th }}$ year, n=0 corresponds to base year.

ii. Total Life Cycle Cost (TLCC):

$$
T L C C=\left(\sum_{n=0}^{N_{p}} \frac{C_{n}}{(1+r)^{n}}\right)-S V
$$

where, $C_{n}=$ Costs incurred during $n^{\text {th }}$ year which comprise of investment, O\&M, replacement and any other cost which is of relevance to project, $S V=$ Present worth of salvage value, $\$$.

iii. Levelized Cost of Energy (LCOE):

$$
L C O E=\frac{T L C C}{\sum_{n=1}^{N_{p}} Q_{n} /(1+r)^{n}}
$$

where, $Q_{n}=$ Energy output during $n^{\text {th }}$ year, $\mathrm{kWh}$

iv. Annualized Capital Cost (ACC):

$$
\begin{aligned}
& A C C=C R F \times N P V \\
& C R F=\frac{r \times(1+r)^{N_{p}}}{(1+r)^{N_{p}}-1}
\end{aligned}
$$

where, $C R F=$ Capital recovery factor

v. Benefit to Cost Ratio (BCR):

$$
B C R=\frac{N P V_{\mathbf{B}}}{N P V_{C}}
$$

where, $N P V_{\mathbf{B}}=$ Net present value of benefits over project life span, $N P V_{C}=$ Net present value of costs over project life span.

In order to provide a comprehensive overview, some important economic evaluation criteria along with their benefits and limitations have been summarised in Table 4.

Table 4 - Review on economic evaluation parameters

\begin{tabular}{llcc}
\hline Reference & Economic index & Advantages & Limitations \\
\hline$[10]$ & NPV & $\begin{array}{c}\text { - Evaluates cost and benefits of } \\
\text { mutually exclusive alternatives. } \\
\end{array}$ & $\begin{array}{c}\text { - Cannot compare projects with } \\
\text { different life spans. } \\
\text { of different alternatives. }\end{array}$
\end{tabular}




\begin{tabular}{|c|c|c|c|}
\hline $\begin{array}{l}{[10,75,68,81,82,} \\
83]\end{array}$ & LCOE & $\begin{array}{l}\text { - Provides a comparison of cost of } \\
\text { energy generated from different } \\
\text { sources or a mix of sources. } \\
\text { - Assists in determining tariff which } \\
\text { must be charged to customer }\end{array}$ & $\begin{array}{l}\text { - Does not acknowledge the } \\
\text { social implications of different } \\
\text { alternatives. }\end{array}$ \\
\hline $\begin{array}{l}{[10,12,45,46,53} \\
56,66]\end{array}$ & TLCC & $\begin{array}{l}\text { - Provides a comparison of costs } \\
\text { associated with different alternatives. }\end{array}$ & $\begin{array}{l}\text { - Does not take into account } \\
\text { benefits associated with the } \\
\text { project. } \\
\text { - Fails to acknowledge } \\
\text { difference between acceptable } \\
\text { and unacceptable costs. }\end{array}$ \\
\hline
\end{tabular}

\begin{tabular}{|c|c|c|c|}
\hline$[5,48,56]$ & $\mathrm{ACC}$ & $\begin{array}{l}\text { - Compares the costing of different } \\
\text { alternatives. } \\
\text { - Serves to give an indication of the } \\
\text { amount of revenue that must be } \\
\text { generated from an investment in } \\
\text { order to ensure project viability. }\end{array}$ & $\begin{array}{l}\text { - Like TLCC, considers only the } \\
\text { costs and not the associated } \\
\text { benefits. }\end{array}$ \\
\hline$[7,45]$ & $\begin{array}{l}\text { Incremental cost } \\
\text { of reliability, } \\
\text { Cost of losses }\end{array}$ & $\begin{array}{l}\text { - Useful in attaining one particular } \\
\text { objective. }\end{array}$ & $\begin{array}{l}\text { - Ignores all other system } \\
\text { evaluation parameters. }\end{array}$ \\
\hline$[44,81]$ & $\begin{array}{l}\text { Total system } \\
\text { costs }\end{array}$ & $\begin{array}{l}\text { - Considers immediate investment } \\
\text { required in system planning. }\end{array}$ & $\begin{array}{l}\text { - Does not give consideration to } \\
\text { evaluation over project } \\
\text { lifespan. }\end{array}$ \\
\hline [84] & BCR & $\begin{array}{l}\text { - Useful in evaluating investments } \\
\text { from societal perspective. }\end{array}$ & $\begin{array}{l}\text { - Not suitable for comparison } \\
\text { between mutually exclusive } \\
\text { alternatives due to different } \\
\text { investment sizes. }\end{array}$ \\
\hline$[51]$ & Payback period & $\begin{array}{l}\text { - Useful in assessing the time period in } \\
\text { which the investment will return. } \\
\text { - Indicative of break-even point }\end{array}$ & $\begin{array}{l}\text { - Does not provide any } \\
\text { indication from consumer's } \\
\text { perspective. }\end{array}$ \\
\hline
\end{tabular}

\section{Conclusion}

This paper puts forward a compendious literature survey on reliability and economic assessment framework of HPS. The objective of review presented in this paper is to facilitate a productive discussion on:

i. Various techniques of solar and wind resource modelling.

ii. Different reliability evaluation criteria along with their specific pros and cons.

iii. Analysis of analytical, simulation and AI based approaches for assessment of system reliability.

iv. Various economic evaluation parameters which can be helpful in assessing financial viability of hybrid power system.

For the analysis of above points, about 500 publications from 1995 to 2021 have been reviewed. The most significant ones have been incorporated in the reference list. With the purpose of familiarizing the readers about the inclination of research fraternity towards different techniques, indices and parameters, a contribution in search space has been presented in Fig. 9.

Based on review, it can be stated that the intermittency accompanying solar and wind resources requires a careful system planning to ascertain reliability standards. The use of appropriate modelling techniques can help in predicting solar and wind generation more accurately. This can facilitate planning of hybrid power system with adequate reliability level. The choice of appropriate reliability indices is essential to analyse the specific requirements of system planning. It can also be concluded based on literature survey that simulation based techniques though simple to implement, may prove to be computationally expensive. The analytical techniques can prove to be a befitting option provided appropriate mathematical model is developed. While performing, economic assessment it should be borne in mind that despite of high initial investment, solar and wind resources may prove to be more economical in long run. A careful cost and benefit assessment may help in broadening the vision while gauging financial viability. The reduction in environmental emissions must be considered as an integral part of cost-benefit analysis owing to its direct association with public health and quality of life. 


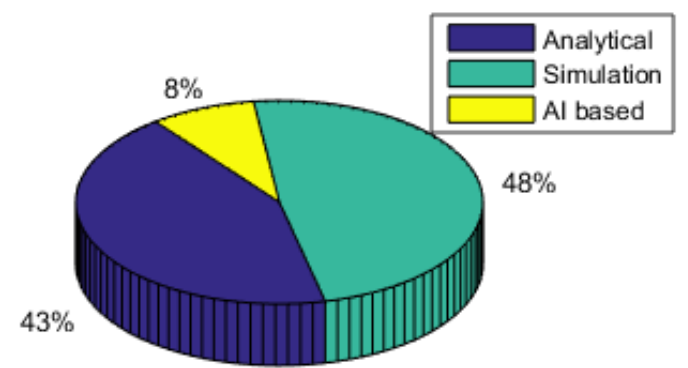

(a) Reliability evaluation techniques

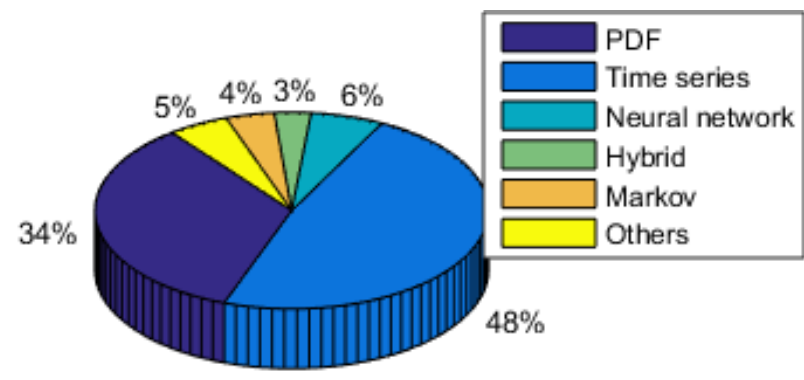

(c) Modelling techniques

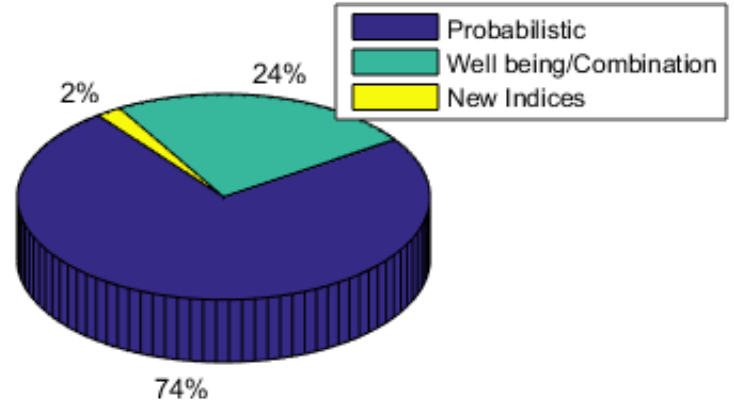

(b) Reliability indices

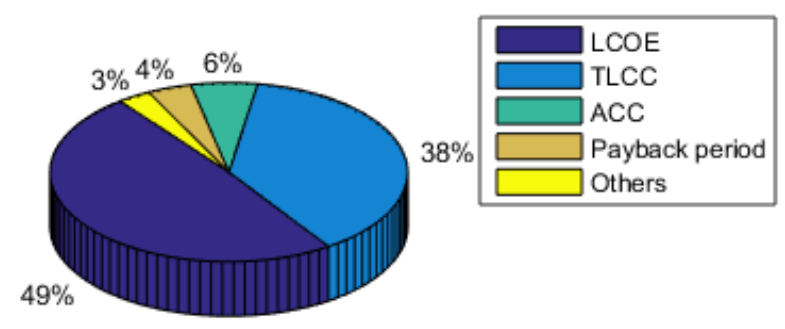

(d) Economic parameters

\section{Fig. 9 - Research space occupied by different components of reliability and economic evaluation}

An effort has been made to cover all major components involved in planning of solar and wind based HPS. The review is intended to provide a quick reference to researchers willing to carry out their research in solar and wind integration. To summarize the review, Table. 5 presents author's critical comments and suggestions for prospective research work in this area.

Table 5 - Author's critical comments

\begin{tabular}{|c|c|c|}
\hline Research area & Author's inference & Future research direction \\
\hline $\begin{array}{l}\text { Reliability } \\
\text { evaluation } \\
\text { technique }\end{array}$ & $\begin{array}{l}\text { - Analytical and simulation approaches have been widely } \\
\text { employed by the researchers. However, both the } \\
\text { techniques have their own share of problems. The } \\
\text { simulation based approaches though simple to } \\
\text { implement may prove computationally expensive when } \\
\text { huge amount of generation combinations are required to } \\
\text { be evaluated. Analytical techniques, on the other hand, } \\
\text { become complicated to implement once the system } \\
\text { complexity increases. }\end{array}$ & $\begin{array}{l}\text { - AI based techniques and hybrid } \\
\text { approaches which integrate the } \\
\text { characteristics of analytical and } \\
\text { simulation methods need to be } \\
\text { further explored. }\end{array}$ \\
\hline $\begin{array}{l}\text { Reliability } \\
\text { Indices }\end{array}$ & $\begin{array}{l}\text { - Based on literature, it can be established that a lot of } \\
\text { work is focused on conventional probabilistic indices. } \\
\text { - These indices are sufficient to exhibit the system } \\
\text { characteristics with conventional dispatchable } \\
\text { generator. However, they might prove inadequate to } \\
\text { impart clarity to system state in the presence of } \\
\text { stochastic RES. }\end{array}$ & $\begin{array}{l}\text { - With increasing penetration of } \\
\text { RES, it is desirable to develop new } \\
\text { indices which are capable of } \\
\text { capturing the inherent randomness } \\
\text { associated with these resources. }\end{array}$ \\
\hline $\begin{array}{l}\text { Economic } \\
\text { analysis }\end{array}$ & $\begin{array}{l}\text { - Almost all of the system planning studies reported in } \\
\text { literature have considered economic evaluation as an } \\
\text { integral component. However, the economic parameters } \\
\text { are mostly associated with the capital cost of generators, } \\
\text { operating and maintenance cost. } \\
\text { - With the increasing environmental awareness, the } \\
\text { harmful effects of emission on human health and quality } \\
\text { of life has been strongly asserted. However, very few } \\
\text { studies report embed the social effects in the economic } \\
\text { planning of micro-grid projects. }\end{array}$ & $\begin{array}{l}\text { - Research may be directed in the } \\
\text { direction where in addition to cost } \\
\text { parameters, economic evaluation } \\
\text { considers the other benefits of } \\
\text { RES sources on society. } \\
\text { - In order to do so, economic } \\
\text { benefits in terms of reduced health } \\
\text { cost, job development, human } \\
\text { satisfaction index should also be } \\
\text { incorporated in economic analysis. }\end{array}$ \\
\hline
\end{tabular}


Modelling of $\quad$ Though a wide variety of techniques have been reported RES

for modelling of RES, there still remains a need to improve the accuracy of the techniques. This is particular essential for long term forecasting which forms the basis for generation capacity planning.
- Need to focus on hybrid approaches to further improve the accuracy.

\section{References}

[1] Paliwal, P., Patidar, N. P. \& Nema, R.K. (2014). Planning of grid integrated distributed generators: A review of technology, objectives and techniques. Renewable and Sustainable Energy Reviews, 40, 557-570. doi: 10.1016/j.rser.2014.07.200

[2] Wankhede S. K. , Paliwal, P. \& Kirar, M.K.(2020). Increasing Penetration of DERs in Smart Grid Framework: A State-of-the-Art Review on Challenges, Mitigation Techniques and Role of Smart Inverters. Journal of circuits, systems and computers. https://doi.org/10.1142/S0218126620300147

[3] Peri, P. G. V., Paliwal, P. \& Joseph, F. C. (2017). ACMC-based hybrid AC/LVDC micro-grid. IET Renewable Power Generation, 11, 4, 521-528, 15 3. doi: 10.1049/iet-rpg.2016.0389

[4] Syafaruddin (2019). Review on Multi-Objectives Optimization Methods in Hybrid Power Generation. Journal of Engineering Science and Technology Review, 12, 143-152. doi. 10.25103/jestr.121.17

[5] Karaki, S. H., Chedid, R. B. \& Ramdan, R. (2000). Probabilistic production costing of diesel-wind energy conversion systems. IEEE Trans. on Energy Conversion, 15, 3, 284-289. doi: 10.1109/60.875494

[6] Ahmed Shata, A. S. \& Hanitsch, R. (2006). Evaluation of wind energy potential and electricity generation on the coast of Mediterranean Sea in Egypt. Renewable Energy, 31, 8, 1183-1202. https://doi.org/10.1016/j.renene.2005.06.015

[7] Atwa, Y. M., El-Saadany, E. F., Salama, M. M. A. \& Seethapathy, R., "Optimal renewable resources mix for distribution system energy loss minimization”, IEEE Trans. Power Syst., vol.25, no. 1, pp. 360-370, Feb. 2010. doi: 10.1109/TPWRS.2009.2030276

[8] Khatod, D. K., Pant, V. \& Sharma, J. (2010). Analytical approach for well-being assessment of small autonomous power systems with solar and wind energy sources. IEEE Trans. Energy Conversion, 25, 2, 535545. doi: 10.1109/TEC.2009.2033881

[9] Paliwal, P., Patidar, N. P. \& Nema, R.K. (2014). A novel method for reliability assessment of autonomous PV-wind-storage system using probabilistic storage model. Int. J. Electr. Power Energy System, 55, 692703. https://doi.org/10.1016/j.ijepes.2013.10.010

[10] Paliwal, P., Patidar, N. P. \& Nema, R.K. (2014). Determination of reliability constrained optimal resource mix for an autonomous hybrid power system using Particle Swarm Optimization. Renewable Energy, 63, 194-204. https://doi.org/10.1016/j.renene.2013.09.003

[11] Paliwal, P., Patidar, N. P. \& Nema, R.K. (2020). Probabilistic indices for analyzing the impact of DER penetration on system reliability. IET Renewable Power Generation. doi: 10.1049/iet-rpg.2019.1214

[12] Ma, G., Xu, G., Chen, Y. \& Ju, R. (2017). Multi-objective optimal configuration method for a standalone wind-solar-battery hybrid power system. IET Renewable Power Generation, 11, 1, 194-202. http://dx.doi.org/10.1049/iet-rpg.2016.0646

[13] Garcia, A., Torres, J. L., Prieto, E. \& De Francisco, A. (1998). Fitting wind speed distributions: a case study. Solar Energy, 62, 2, 139-144. https://doi.org/10.1016/S0038-092X(97)00116-3

[14] India Meteorological Department (2009). Solar Radiant Energy over India. Ministry of Earth Sciences.

[15] Santhosh, M., Chintham, V. \& Kumar, D.M. (2020). Current advances and approaches in wind speed and wind power forecasting for improved renewable energy integration: A review. Engineering Reports, 2, 10. https://doi.org/10.1002/eng2.12178

[16] Jangamshetti, S. H. \& Rau, V.G. (1999). Site matching of wind turbine generators: a case study. IEEE Trans. Energy Conversion, 14, 4, 1537-1543. doi: 10.1109/60.815102

[17] Mani, A. (1992). Wind Energy Resource Survey in India-II. Allied Publishers Limited

[18] Yang, H., Lu, L. \& Zhou, W. (2007). A novel optimization sizing model for hybrid solar-wind power generation system. Solar Energy, 81, 1, 76-84. https://doi.org/10.1016/j.solener.2006.06.010

[19] Kaminsky, F. C., Kirchhoff, R. H., Syu, C. Y. \& Manwell, J. F. (1991). A comparison of alternative approaches for the synthetic generation of wind speed time series. J. Solar Engineering,113, 4, 280-289, Nov. doi: 10.1115/1.2929974

[20] Sfetsos, A. (2000). A comparison of various forecasting techniques applied to mean hourly wind speed time series, Renewable Energy, 21, 1, 23-35. doi: 10.1016/S0960-1481(99)00125-1

[21] Castino, F., Festa, R. \& Ratto, C.F. (1998). Stochastic modelling of wind velocities time series. J. Wind Eng. and Ind. Aerodynamics, 74-76, 141-151. https://doi.org/10.1016/S0167-6105(98)00012-9

[22] Almorox, J. \& Hontoria, C. (2004). Global solar radiation estimation using sunshine duration in Spain. Energy Convers. and Management, 45, 9-10, 1529-1535. https://doi.org/10.1016/j.enconman.2003.08.022 
[23] Bulut, H. \& Büyükalaca, O. (2007). Simple model for the generation of daily global solar radiation data in Turkey. Appl. Energy, 84, 5, 477-491. https://doi.org/10.1016/j.apenergy.2006.10.003

[24] Rensheng, C., Shihua, L., Ersy, K., Jianping, Y. \& Xibin, J. (2006). Estimating daily global radiation using two types of revised models in China. Energy Convers. and Management, 47, 7-8, 865-878. https://doi.org/10.1016/j.enconman.2005.06.015

[25] Sulaiman, M. Y., HlaingOo, W. M., Wahab, M. A. \& Sulaiman, Z.A. (1997). Analysis of residuals in daily solar radiation time series. Renewable Energy, 11, 1, 97-105. https://doi.org/10.1016/S0960-1481(96)001103

[26] Tiba, C. \& Fraidenraich, N. (2004). Analysis of monthly time series of solar radiation and sunshine hour in tropical climates. Renewable Energy, 29, 7, 1147-1160. https://doi.org/10.1016/j.renene.2003.11.016

[27] Aksoy, H., Toprak, Z. F., Aytek, A. \& Erdem U“* nal, N. (2004). Stochastic generation of hourly mean wind speed data. Renewable Energy, 29, 2111-2131. https://doi.org/10.1016/j.renene.2004.03.011

[28] Stedinger, J. R., Vogel, R. M. \& Foufoula-Georgiou, E. (1993). Frequency analysis of extreme events. Handbook of Hydrology, D. Maidment (ed.), McGraw-Hill, Inc., New York.

[29] Shamshad, A., Bawadi, M. A., Wan Hussin, W. M. A., Majid, T.A. \& Sanusi, S. A. M. (2005). First and second order Markov chain models for synthetic generation of wind speed time Series. Energy, 30, 5, 693708. https://doi.org/10.1016/j.energy.2004.05.026

[30] Dukes, M. D. G. \& Palutikof, J. P. (1995). Estimation of extreme wind speeds with very long return periods. J. Appl. Meteorology, 34, 9, 1950-1961. doi: 10.2307/26187416

[31] Sahin, A. D. \& Sen, Z. (2001). First-order Markov chain approach to wind speed modelling. J. Wind Eng. and Ind. Aerodynamics, 89, 3-4, 263-269. https://doi.org/10.1016/S0167-6105(00)00081-7

[32] Torre, M. C., Poggi, P. \& Louche, A. (2001). Markovian model for studying wind speed time series in Corsica. Int. J. Renewable Energy Eng., 3, 2

[33] Lei, M.A., Shiyan, L., Chuanwen, Jiang, Hongling, L. \& Yan, Z. (2009). A review on the forecasting of wind speed and generated power. Renew sustain energy reviews, 13, 915-920. https://doi.org/10.1016/j.rser.2008.02.002

[34] Kalogirou, S.A. (2001). Artificial neural networks in renewable energy systems applications: a review. Renew sustain energy reviews, 5, 373-401. https://doi.org/10.1016/S1364-0321(01)00006-5

[35] Shi, J., Guo, J. \& Zheng, S. (2012). Evaluation of hybrid forecasting approaches for wind speed and power generation time series. Renew sustain energy reviews, 16, 3471-3480. https://doi.org/10.1016/j.rser.2012.02.044

[36] Atwa, Y.M. \& El- Saadny, E.F. (2009). Annual wind speed estimation utilizing constrained grey predictor. IEEE Trans. Energy Conversion, 24, 2, 548-550. doi: 10.1109/TEC.2009.2015973

[37] Sharifian, A., Ghadi, M.J., Ghavidel, S., Li, L. \& Zhang, J. (2018). A new method based on Type-2 fuzzy neural network for accurate wind power forecasting under uncertain data. Renew Energy, 120, 220-230. https://doi.org/10.1016/j.renene.2017.12.023

[38] Meyyappan, U. (2018). Wavelet neural network-based wind speed forecasting and application of shuffled frog leap algorithm for economic dispatch with prohibited zones incorporating wind power. Wind Eng, 42, 1, 3-15. https://doi.org/10.1177/0309524X17723208

[39] Shao, H., Deng, X. \& Fang, C. (2016). Short-term wind speed forecasting using the wavelet decomposition and AdaBoost technique in wind farm of East China. IET Gener Transm Distribution, 10, 11, 2585-2592. doi. 10.1049/iet-gtd.2015.0911

[40] Liu, J., Wang, X. \& Lu, Y. (2017). A novel hybrid methodology for short-term wind power forecasting based on adaptive neuro-fuzzy inference system. Renew Energy, 103, 620-629. https://doi.org/10.1016/j.renene.2016.10.074

[41] Gaxiola, F., Melin, P., Valdez, F., Castro, J.R. \& Castillo, O. (2016). Optimization of type-2 fuzzy weights in backpropagation learning for neural networks using GA and PSO. Appl Soft Computing, 38, 860-871. https://doi.org/10.1016/j.asoc.2015.10.027

[42] Sarkar, D. \& Odyuo, Y. (2019). An ab initio issues on renewable energy system integration to grid. International journal of sustainable energy planning and management,23, https://doi.org/10.5278/ijsepm.2802

[43] Al-Muhaini, M., Bizrah, A., Heydt, G., \& Khalid, M. (2019). Impact of wind speed modelling on the predictive reliability assessment of windbased microgrids. IET Renewable Power Generation, 13, (15), 2947-2956. https://doi.org/10.1049/iet-rpg.2019.0596

[44] Jafari, A., Khalili, T., Ganjehlou, H.G. \& Bidram, A. (2020). Optimal integration of renewable energy sources, diesel generators, and demand response program from pollution, financial, and reliability viewpoints: A multi-objective approach. Journal of Cleaner Production, 247, 119100. https://doi.org/10.1016/j.jclepro.2019.119100 
[45] Paliwal, P. (2020). Reliability constrained planning and sensitivity analysis for Solar-Wind-Battery based Isolated Power System. International journal of sustainable energy planning and management. http://dx.doi.org/10.5278/ijsepm.4599

[46] Saberi, M. , Ahmadi, S.A., Ardakani, F.J. \& Riahy, G.H. (2018). Optimal sizing of hybrid PV and wind energy system with backup of redox flow battery to postpone grid expansion investments", Journal of Renewable and Sustainable Energy, 10, 055903. https://doi.org/10.1063/1.5041448

[47] Karaki, S. H., Chedid, R. B. \& Ramdan, R. (1999). Probabilistic performance assessment of wind energy conversion systems. IEEE Trans. Energy Conversion, 14, 2, 217-224. doi: 10.1109/60.766986

[48] Meschede, H., Hesselbach, J. \& Michael, C. (2019). On the impact of probabilistic weather data on the economic design of renewable energy systems - a case study on La Gomera islands. International Journal of Sustainable Energy Planning and Management, 23, 15-26. https://doi.org/10.5278/ijsepm.3142

[49] Akram, U., Khalid, M., Shafiq, S. (2018). Optimal sizing of a wind/solar/battery hybrid grid-connected microgrid system. IET Renewable Power Generation, 12, (1), 72 - 80

[50] Paliwal Priyanka. Comprehensive analysis of distributed energy resource penetration and placement using probabilistic framework. IET Renew Power Gener. 2021,15:794-808. https://doi.org/10.1049/rpg2.12069.

[51] Kestane, Ö., Koray, Ü. (2017). Techno-economic analysis of wind power plants: A case study of MilasTurkey. Energy Sources, Part B: Economics, Planning, and Policy, 12, 12,10881100. doi: 10.1080/15567249.2017.1376005

[52] Radosavljević, J., Arsić, N., Milovanović, M. \& Ktena, A. (2020). Optimal Placement and Sizing of Renewable Distributed Generation Using Hybrid Metaheuristic Algorithm. Journal of Modern Power Systems and Clean Energy, 8, 3, 499-510. doi: 10.35833/MPCE.2019.000259

[53] Zhang, Y., Wang, J., Berizzi, A. \& Cao, X. (2018). Life cycle planning of battery energy storage system in off-grid wind-solar-diesel microgrid. IET Generation, Transmission Distribution, 12, 20, 4451-4461, 13 11, doi: 10.1049/iet-gtd.2018.5521

[54] Thapa, S., Karki, R. \& Billinton, R. (2013). Utilization of the Area Risk Concept for Operational Reliability Evaluation of a Wind-Integrated Power System. IEEE Transactions on Power Systems, 28, 4, 4771-4779. doi: 10.1109/TPWRS.2013.2264904

[55] Wang L. \& Singh, C. (2008). Population based intelligent search intelligent search in reliability evaluation of generation system with wind penetration. IEEE Trans. Power System, 23, 3, 1336-1345. doi: 10.1109/TPWRS.2008.922642

[56] Wang L. \& Singh, C. (2009). Multicriteria Design of Hybrid Power Generation Systems Based on a Modified Particle Swarm Optimization Algorithm. IEEE Transactions on Energy Conversion, 24, 1, 163-172. doi: 10.1109/TEC.2008.2005280

[57] Zhou, H., Zhang, Y., Yang, L., Liu, Q., Yan, K. \& Du, Y. (2019). Short-Term Photovoltaic Power Forecasting Based on Long Short Term Memory Neural Network and Attention Mechanism. IEEE Access, 7, 78063-78074. doi: 10.1109/ACCESS.2019.2923006

[58] Bui, K.-T. T., Tien Bui, D., Zou, J., Van Doan, C., \& Revhaug, I. (2016). A novel hybrid artificial intelligent approach based on neural fuzzy inference model and particle swarm optimization for horizontal displacement modeling of hydropower dam. Neural Computing and Applications, 29(12), 14951506. doi:10.1007/s00521-016-2666-0

[59] Billinton, R., \& Allan, R. N. (1996). Reliability evaluation of power systems, $2^{\text {nd }}$ Edition, Plenum Press, NY.

[60] Billinton, R. \& Karki, R. (1999). Capacity planning in small isolated power systems using probabilistic methods. IEE Proceedings on Generation, Transmission and Distribution, 146, 1, 61-64. doi: 10.1049/ipgtd:19990043

[61] Billinton, R. \& Karki, R. (1999). Capacity reserve assessment using system well-being analysis. IEEE Trans. on Power System, 14, 2, 433-438. doi: 10.1109/59.761861

[62] Abouzahr, I. \& Ramakumar, R. (1991). Loss of power supply probability of stand-alone photovoltaic systems: A closed form solution approach. IEEE Trans. Energy Conversion, 6, 1, 1-11. doi: $10.1109 / 60.73783$

[63] Gavanidou, E. S., Bakirtzis, A. G. \& Dokopoulos, P. S. (1993). A probabilistic method for the evaluation of the performance and the reliability of wind- diesel energy systems. IEEE Trans. Energy Conversion, 8, 2, 197-206. doi: 10.1109/60.148561

[64] Yang, D., Jiang, C., Cai, G. \& Huang, N. (2019). Optimal sizing of a wind/solar/battery/diesel hybrid microgrid based on typical scenarios considering meteorological variability. IET Renewable Power Generation, 13, 9, 1446-1455, 8 7. doi: 10.1049/iet-rpg.2018.5944

[65] Combe, M., Mahmoudi, A., Haque, M. H. \& Khezri, R. (2019). Optimal sizing of an AC-coupled hybrid power system considering incentive-based demand response. IET Generation, Transmission Distribution, 13, 15, 3354-3361, 6 8. doi: 10.1049/iet-gtd.2018.7055 
[66] Bakhtiari, H. \& Naghizadeh, R. A. (2018). Multi-criteria optimal sizing of hybrid renewable energy systems including wind, photovoltaic, battery, and hydrogen storage with $\varepsilon$-constraint method. IET Renewable Power Generation, 12, 8, 883-892, 11 6. doi: 10.1049/iet-rpg.2017.0706

[67] Benidris, M., Mitra, J., \& Elsaiah, S. (2015). Power system reliability evaluation using a state space classification technique and particle swarm optimization search method. IET Generation, Transmission \& Distribution, 9(14), 1865-1873. doi:10.1049/iet-gtd.2015.0581

[68] Gabbar, H. A., Abdussami, M. R. \& Adham, M. I. (2020). Optimal Planning of Nuclear-Renewable MicroHybrid Energy System by Particle Swarm Optimization. IEEE Access, 8, 181049-181073. doi: 10.1109/ACCESS.2020.3027524

[69] Seyed, H., Arezoo, H., Miadreza, S.K. \& João, C. (2019). Optimal Sizing and Siting of Smart Micro-grid Units under High Renewables Penetration Considering Demand Response. IET Renewable Power Gener, 13, 10, 1809-1822. 10.1049/iet-rpg.2018.6015

[70] Conti, S., Nicolosi, R., Rizzo, S.A. (2012). Generalized Systematic Approach to Assess Distribution System Reliability with Renewable Distributed Generators and Microgrids. IEEE Trans. Power Deliv., 27, 261-270.

[71] Bagheri, A., Monsef, H., Lesani, H. (2015). Integrated distribution network expansion planning incorporating distributed generation considering uncertainties, reliability, and operational conditions. Int. J. Electr. Power Energy Syst., 73, 56-70.

[72] Xu, X., Mitra, J., Wang, T., Mu, L. (2016). Reliability Evaluation of a Microgrid Considering its Operating Condition. J. Electr. Eng. Technol., 11, 47-54

[73] Chen, B., Zhang, X., Zhang, B., Wang, L., Li, W., Wang, S. (2018). Multi-microgrids system reliability assessment algorithm considering energy dispatch strategy among microgrids. Energy Procedia, 145, 15-19.

[74] Zhong, W., Wang, L., Liu, Z., Hou, S. (2020). Reliability Evaluation and Improvement of Islanded Microgrid Considering Operation Failures of Power Electronic Equipment. J. Mod. Power Syst. Clean Energy, 8, 111123

[75] Silva da, A. M. L., Resende de, L. C., Fonseca da, Manso L. A. \& Miranda V. (2008). Artificial Neural Networks Applied to Reliability and Well-Being Assessment of Composite Power Systems. Proceedings of the $10^{\text {th }}$ International Conference on Probablistic Methods Applied to Power Systems.1-6

[76] Billinton, R. \& Karki, R. (1999). Application of Monte Carlo Simulation to generating system well-being analysis. IEEE Trans. Power System, 14, 3, 1172-1177. doi: 10.1109/59.780954

[77] Abouzahr, I. \& Ramakumar, R. (1990). Loss of power supply probability of stand-alone wind energy conversion systems: A closed form solution approach. IEEE Trans. Energy Conversion. 5, 3, 445-452. doi: $10.1109 / 60.105267$

[78] Saramourtsis, A. C., Bakirtzis, A. G., Dokopoulos, P. S. \& Gavanidou, E. S. (1994). Probabilistic evaluation of the performance of Wind-Diesel energy systems. IEEE Trans Energy Conversion, 9, 4, 743-752. doi: $10.1109 / 60.368332$

[79] Billinton, R. \& Karki, R. (2001). Maintaining supply reliability of small isolated power systems using renewable energy. IEE Proc. Generation, Transmission and Distribution, 148, 6, 530-534. doi: 10.1049/ipgtd:20010562

[80] Owens, G. (2002). Best practices guide: economic and financial evaluation of renewable energy projects. Alternative Energy Develop., Washington

[81] Mellouk, L., Ghazi, M., Aaroud, A., Boulmalf, M., Benhaddou, D. \& Zine-Dine, K. (2019). Design and energy management optimization for hybrid renewable energy system- case study: Laayoune region. Renewable Energy, 139, 621-634. https://doi.org/10.1016/j.renene.2019.02.066

[82] Lozano, L., Querikiol, E.M., Abundo, M.L.S. \& Bellotindos, L.M. (2019). Techno-economic analysis of a cost-effective power generation system for off-grid island communities: A case study of Gilutongan Island, Cordova, Cebu, Philippines. Renewable Energy, 140, 905-911. https://doi.org/10.1016/j.renene.2019.03.124

[83] Shen, W. et al. (2020). A comprehensive review of variable renewable energy levelized cost of electricity. Renewable and Sustainable Energy Reviews, 133, 110301. doi:10.1016/j.rser.2020.110301

[84] Xia, S., Chan, K.W., Luo, X., Bu, S., Ding, Z. \& Zhou, B. (2018). Optimal sizing of energy storage system and its cost-benefit analysis for power grid planning with intermittent wind generation. Renewable Energy, 122, 472-486. https://doi.org/10.1016/j.renene.2018.02.010 